\title{
SUPER-STABILITY AND STABILITY \\ OF THE EXPONENTIAL EQUATIONS
}

\section{Lu Xu, Huai-Xin CaO, Wen-Ting Zheng and Zhen-Xia Gao}

Abstract. In this paper, we introduce the concepts of super-stability, stability, $\delta$-Ger-stability of the exponential equation of an operator from a normed space into a normed algebra. By using some results due to J. Baker and R. Ger, we obtain some new conclusions about these stabilities. Mathematics subject classification (2010): Primary 39B52, secondary 39B82, 46B99, 17A40. Keywords and phrases: Super-stability, stability, $\delta$-Ger-stability, exponential equation.

\section{REFERENCES}

[1] S. M. Ulam, A Collection of the Mathematical Problems, Interscience Publ., New York, 1960.

[2] D. H. Hyers, On the stability of the linear functional equation, Proc. Nat. Acad. Sci. USA., 27 (1941), 222-224.

[3] TH. M. Rassias, On the stability of the linear mapping in Banach spaces, Proc. Amer. Math. Soc., 72 (1978), 297-300.

[4] G. L. FORTI, Hyers-Ulam stability of functional equations in several variables, Aequationes Math. 50 (1995), 143-190.

[5] TH. M. RASSiAs, On the stability of functional equations and a problem of Ulam, Acta Appl. Math., 62 (2000), 23-130.

[6] D. G. BourgIN, Approximately isometric and multiplicative transformations on continuous function rings, Duke Math. J., 16 (1949), 385-397.

[7] J. Baker, J. Lawrence, F. Zorzitto, The stability of the equation $f(x+y)=f(x) f(y)$, Proc. Amer. Math. Soc., 74 (1979), 242-246.

[8] J. BAKeR, The stability of the cosine equation, Proc. Amer. Math. Soc., 80 (1980), 411-416.

[9] R. Ger, P. Š EMrL, The stability of the exponential equation, Proc. Amer. Math. Soc., 124 (1996), 779-787.

[10] F. Skof, Sull approssimazione delle applicazioni localmente $\delta$-additive, Atti Accad. Sc. Torino, 117 (1983), 377-389.

[11] T. AOKI, On the stability of the linear transformation in Banach spaces, J. Math. Soc. Japan, 2 (1950), 64-66.

[12] L. MALigRAnda, A result of Tosio Aoki about a generalization of Hyers-Ulam stability-Rassias stability of additive functions-a question of priority, Aequationes Math., 75 (2008), 289-296.

[13] Zhen-Xia Gao, Huai-Xin CaO, Wen-Ting Zheng and Lu Xu, Generalized Hyers-UlamRassias stability of functional inequalities and functional equations, J. Math. Inequal., 3 (2009), $63-$ 77.

[14] Deng-Hua Zhang, Huai-Xin CaO, Stability of group and ring homomorphisms, Math. Inequal. \& Appl., 9 (2006), 521-528. 